\title{
Boron Particle Ignition in Secondary Chamber of Ducted Rocket
}

\author{
J. X. Hu, Z. X. Xia, W. H. Zhang, Z. B. Fang, D. Q. Wang, and L. Y. Huang \\ College of Aerospace and Materials Engineering, National University of Defense Technology, Changsha 410073, China
}

Correspondence should be addressed to Z.X.Xia, xiazhixun@nudt.edu.cn

Received 6 October 2011; Accepted 15 December 2011

Academic Editor: Valsalayam Sanal Kumar

Copyright $\odot 2012$ J. X. Hu et al. This is an open access article distributed under the Creative Commons Attribution License, which permits unrestricted use, distribution, and reproduction in any medium, provided the original work is properly cited.

\begin{abstract}
In the secondary chamber of ducted rocket, there exists a relative speed between boron particles and air stream. Hence, the ignition laws under static conditions cannot be simply applied to represent the actual ignition process of boron particles, and it is required to study the effect of forced convective on the ignition of boron particles. Preheating of boron particles in gas generator makes it possible to utilize the velocity difference between gas and particles in secondary chamber for removal of the liquid oxide layer with the aid of Stoke's forces. An ignition model of boron particles is formulated for the oxide layer removal by considering that it results from a boundary layer stripping mechanism. The shearing action exerted by the high-speed flow causes a boundary layer to be formed in the surface of the liquid oxide layer, and the stripping away of this layer accounts for the accelerated ignition of boron particles. Compared with the King model, as the ignition model of boron particles is formulated for the oxide layer removal by considering that it results from a boundary layer stripping mechanism, the oxide layer thickness thins at all times during the particle ignition and lower the ignition time.
\end{abstract}

\section{Introduction}

Systematic advances in missile propulsion systems technology have provided large increases in missile performance capabilities. Replacement of much of solid propellant rocket oxidizer with free stream air, as in the ducted rocket concept, offers over 5 to 1 increase in missile range capability [1]. Boron has been considered for many years as a prime candidate used for increasing the ducted rocket capabilities based on its high potential energy release on both a volumetric and gravimetric basis coupled with a high energy of combustion, high combustion temperature, and low-molecular-weight products [2]. These properties make boron an attractive material for use in ducted rocket propellants [3]. In order for these advantages to be realized, however, the boron particles must ignite and burn completely within a very limited residence time. Since boron particles are generally initially coated with an oxide layer with inhibits combustion and since boron has an extremely high boiling point, which necessitates surface burning subsequent to oxide removal, this can become difficult, particularly under adverse operating conditions [4].

In previous work, two scenarios for boron ignition and combustion have been identified, which differ in the controlling element in the overall process mechanism [5]. Two controversial theories remain to be resolved for describing boron ignition (removal of oxide coating) in terms of the rate limiting steps $[4,6,7]$. Previous experiments of Macek and semple [8] and Li and Williams [7] have demonstrated that when the boron particle temperature is high (e.g., $1800 \mathrm{~K}$ ), the rate of boron diffusion exceeds the rate of oxygen diffusion across the oxide layer. Recent experimental observations indicating significant agglomeration and liquefaction of boron at $1213 \mathrm{~K}$ in both $\mathrm{O}_{2}$ and Ar environments have also been interpreted as evidence supporting the diffusion of boron instead of oxygen within the oxide coating as the limiting process $[3,9]$.

Because ignition and combustion of boron particles involve the release of heat, layer evolution assumes the form of a thermo-hydrodynamic process, coupled with the solid boron substrate underneath and with the ambient oxidizing atmosphere, which is assumed to be stagnant [5]. It is important to note that most the current models of boron particles ignition constrain the symmetry to be conserved. That is to say that the oxidizing atmosphere is assumed to be stagnant and uniform if the particle and its initial oxide layer are given to be spherically symmetric. In the secondary 
combustion chamber of ducted rocket, there always exists a relative speed between the boron particle and air stream [10]. Hence, the ignition laws under static conditions cannot be simply applied to represent the actual ignition process of boron particles, and it is required to study the effect of forced convective on the ignition of the boron particle. Much research has been conducted to study the ignition of the boron particle, both experimentally and theoretically, in pure oxygen and other atmospheres, with relatively little work available on ignition of the boron particle under forced convection conditions $[11,12]$. Dirk Meinkohn developed a thin model to allow the oxide flow field to be derived in the creeping-flow approximation and demonstrated that boron particle ignition may then be caused by the Marangoni effect, which is shown to entail the spreading of punctures and ruptures in the oxide layer, leading to layer thinning or even complete layer removal $[13,14]$. Preheating of the boron particles in gas generator makes it possible to utilize the velocity difference between gas and particles in secondary chamber for removal of the liquid oxide layer with the aid of Stokes' forces. Povitsky and Goldman demonstrated there is indication of regime of fast ignition enhanced by Stokes' forces by experimentally and numerical simulation [15].

The object of this study is to investigate the oxide layer movement and to characterize its influence on ignition of boron particles in the case of high initial relative particle velocity. An ignition model of boron particles is formulated for the oxide layer removal by considering that it results from a boundary layer stripping mechanism.

\section{Formulation}

\subsection{Boundary Layer Stripping Analysis}

2.1.1. Assumptions. The movement of the oxide layer on the front half-surface of the boron particle is shown schematically in Figure 1, using a spherical coordinate system with the particle center as origin. $x$ is the curvilinear coordinate along the interface separating the two fluids and $y$ is the coordinate perpendicular to it. $y=0$ represents the interface between the gas layer and liquid oxide one. $y=+\infty$ represents the value of gas boundary layer. $y=-\infty$ represents the value of liquid boundary layer. $u_{g}, u_{l}$ represent fluid velocity in gas or liquid boundary layer. $R$ is the radius of the boron particle. $X$ is the thickness of liquid oxide layer. $U_{\infty}$ represents gas freestream velocity. $U(x)$ represents gas fluid velocity around the boron particle.

In order to solve the problem of liquid oxide layer movement, the following assumptions are adopted.

(1) The temperature inside and around the boron particle is uniformity.

(2) The flow is steady and incompressible.

(3) There is no flow separation at the interface between solid particle and liquid oxide layer.

(4) The value of liquid oxide boundary layer is less than the thickness of liquid oxide layer.

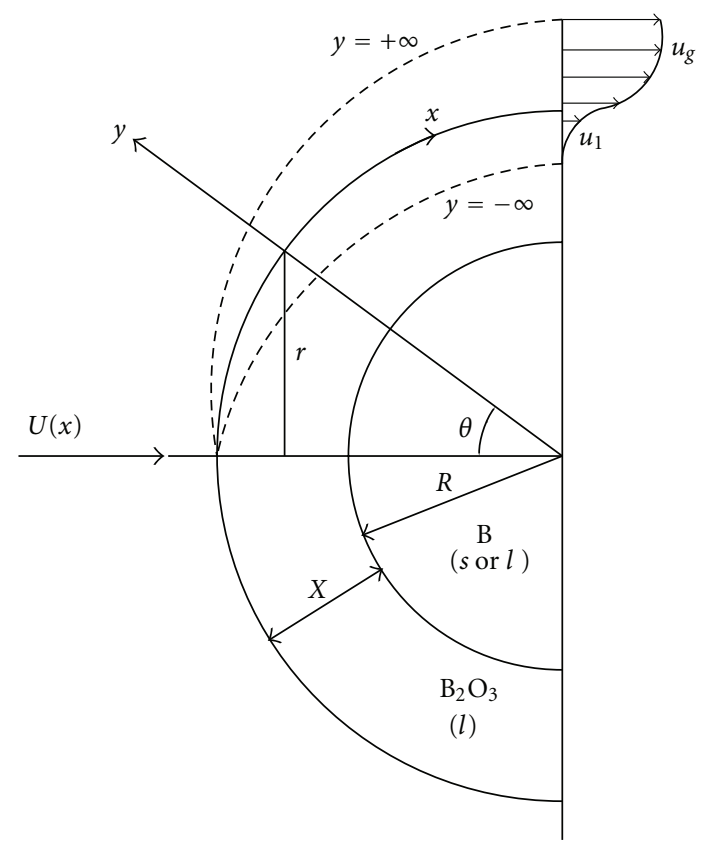

FIGURE 1: Scheme of oxide layer movement relative to surface of flowing boron particles.

(5) The boron particle shape can be approximated by a sphere for the simplified analysis here, the oxide layer thickness is much smaller than particle radius, and hence the gas fluid velocity around the boron particle can be represented in the following expression:

$$
U(x)=1.5 U_{\infty} \sin \frac{x}{R}
$$

(6) Equating the shear stress in the gas layer to that in the liquid layer at the interface yields the following equation:

$$
\left(\mu_{g} \frac{\partial u_{g}}{\partial y}\right)_{y=0}=\left(\mu_{l} \frac{\partial u_{l}}{\partial y}\right)_{y=0}
$$

(7) The pressure gradient in the gas layer and the liquid layer is equal:

$$
\left(\frac{\partial P}{\partial x}\right)_{l}=\left(\frac{\partial P}{\partial x}\right)_{g}
$$

2.1.2. Equations and Solution. An approximate solution to the two-boundary-layer problem can be obtained by assuming arbitrary simple velocity distributions containing a few parameters and the using the momentum differential relations to determine three parameters [16]. If we assume that the flow is steady and incompressible, then it yields the boundary-layer differential equations for the gas and for the liquid. 
The basic equations for the gas is given by

$$
\begin{gathered}
\frac{\partial\left(u_{g} r\right)}{\partial x}+\frac{\partial\left(v_{g} r\right)}{\partial y}=0 \\
u_{g} \frac{\partial u_{g}}{\partial x}+v_{g} \frac{\partial u_{g}}{\partial y}=-\frac{1}{\rho_{g}} \frac{\partial P}{\partial x}+\frac{\mu_{g}}{\rho_{g}} \frac{\partial^{2} u_{g}}{\partial y^{2}} .
\end{gathered}
$$

The boundary conditions for equations above is given by

$$
\begin{gathered}
y=0: v_{g}=0, \quad u_{g}=u_{g}(x), \quad \mu_{g} \frac{\partial u_{g}}{\partial y}=\mu_{l} \frac{\partial u_{l}}{\partial y}, \\
y=\infty: u_{g}=U(x)
\end{gathered}
$$

where the pressure gradient in the gas boundary layer is given by

$$
-\frac{1}{\rho_{g}} \frac{\partial P}{\partial x}=U \frac{\partial U}{\partial x} .
$$

Then (4) can be given by

$$
u_{g} \frac{\partial u_{g}}{\partial x}+v_{g} \frac{\partial u_{g}}{\partial y}=U \frac{\partial U}{\partial x}+\frac{\mu_{g}}{\rho_{g}} \frac{\partial^{2} u_{g}}{\partial y^{2}} .
$$

The basic equations for the liquid are given by

$$
\begin{gathered}
\frac{\partial\left(u_{l} r\right)}{\partial x}+\frac{\partial\left(v_{l} r\right)}{\partial y}=0 \\
u_{l} \frac{\partial u_{l}}{\partial x}+v_{l} \frac{\partial u_{l}}{\partial y}=\frac{\rho_{g}}{\rho_{l}} U \frac{\partial U}{\partial x}+\frac{\mu_{l}}{\rho_{l}} \frac{\partial^{2} u_{l}}{\partial y^{2}} .
\end{gathered}
$$
by

The boundary conditions for equations above are given

$$
\begin{gathered}
y=0: v_{l}=0, \quad u_{l}=u_{g}(x), \quad \mu_{l} \frac{\partial u_{l}}{\partial y}=\mu_{g} \frac{\partial u_{g}}{\partial y}, \\
y=-\infty: \mu_{l} \frac{\partial u_{l}}{\partial y}=0 .
\end{gathered}
$$

In order for equations solution, the stream function, $\psi$, is defined by

$$
u=\frac{L}{r} \frac{\partial \psi}{\partial y}, \quad v=-\frac{L}{r} \frac{\partial \psi}{\partial x},
$$

where $L$ denotes the latent length.

Some normalized variable parameters are defined by

$$
\begin{gathered}
\xi=\int_{0}^{x} \frac{r^{2}(x) U(x)}{L^{2} U_{\infty}} d x, \quad \eta=\frac{y U(x) r(x)}{L \sqrt{2 \mu_{g} U_{\infty} \xi / \rho_{g}}}, \\
\psi=G(\eta) \sqrt{\frac{2 \mu_{g} U_{\infty} \xi}{\rho_{g}}} .
\end{gathered}
$$

Then the equations for the gas can be simplified as

$$
G^{\prime \prime \prime}+G G^{\prime \prime}+\beta(\xi)\left(1-G^{2}\right)=0,
$$

where $\beta(\xi)=2 \xi U_{\infty}\left(\left(L^{2} / r^{2}\right) d U / d x\left(1 / U^{2}\right)\right)$.
The boundary conditions for equations above can be simplified as

$$
\begin{gathered}
\eta=0: G=0, \quad G^{\prime}=\bar{u}(x), \\
\eta=\infty: G^{\prime}=1 .
\end{gathered}
$$

Then the equations for the liquid can be simplified as

$$
L^{\prime \prime \prime}+L L^{\prime \prime}+\beta(\xi)\left(\frac{\rho_{g}}{\rho_{l}}-L^{\prime 2}\right)=0 .
$$

The boundary conditions for equations above can be simplified as

$$
\begin{gathered}
\eta=0: L=0, \quad L^{\prime}=G^{\prime}, \quad L^{\prime \prime}=G^{\prime \prime} \Gamma, \\
\eta=-\infty: L^{\prime \prime}=0
\end{gathered}
$$

where $\Gamma=\sqrt{\rho_{g} \mu_{g} /\left(\rho_{l} \mu_{l}\right)}$, gas viscosity $\mu_{g}=6.2 \times 10^{-5} \mathrm{~Pa} \cdot \mathrm{s}$, liquid viscosity $\mu_{l}=3.2 \times 10^{-4} \mathrm{~Pa} \cdot \mathrm{s}$.

After what may seem like an interminable manipulation of the governing equations, we have finally set up that particular form of the equations that will be most appropriate as well as convenient for the gas and liquid boundary layer flow. In order to solve (13) and (15), $G^{\prime}(0)$ and $G^{\prime \prime}(0)$ should be first got. According to literature [17], $G^{\prime}(0)=\bar{u}(x)=$ $\left(\rho_{g} \mu_{g} / \rho_{l} \mu_{l}\right)^{1 / 3}$. Firstly, $G^{\prime \prime}(0)$ is given or estimated, the classical four-order Runge-Kutta method is used to solve these ordinary differential equations. If the obtained boundary values satisfy the actual boundary conditions at the outer edge; namely, $G^{\prime}(+\infty)=1$ and $L^{\prime \prime}(-\infty)=0$, the calculation can be stopped, and the solutions have been found. Otherwise, we have to revise the estimated value of $G^{\prime \prime}(0)$ and repeat the numerical integrating procedure until all the boundary conditions at the outer edge are satisfied.

2.1.3. The Conditions of Aerodynamic Shattering. During aerodynamic shattering, the tangential friction stress is propitious to sweep the liquid oxide layer from solid particle, and the surface tension is unpropitious to sweep the liquid oxide layer.

The tangential friction stress can be expressed by

$$
\tau=\left(\mu_{g} \frac{\partial u_{g}}{\partial y}\right)_{y=0}=\mu_{g} \frac{U^{2} r G^{\prime \prime}(0)}{L \sqrt{2 v_{g} U_{\infty} \xi}}
$$

For a spherical particle, the surface tension can be expressed by

$$
F=\frac{C_{1} \sigma}{R} .
$$

According to literature [15], the constant $C_{1}=2.0$ and the coefficient of surface tension $\sigma=0.01$.

We and Re can be expressed by

$$
\mathrm{We}=\frac{\rho_{g} u_{r}^{2} d_{p}}{\sigma}, \quad \operatorname{Re}=\frac{\rho_{g} u_{r} d_{p}}{\mu_{g}},
$$




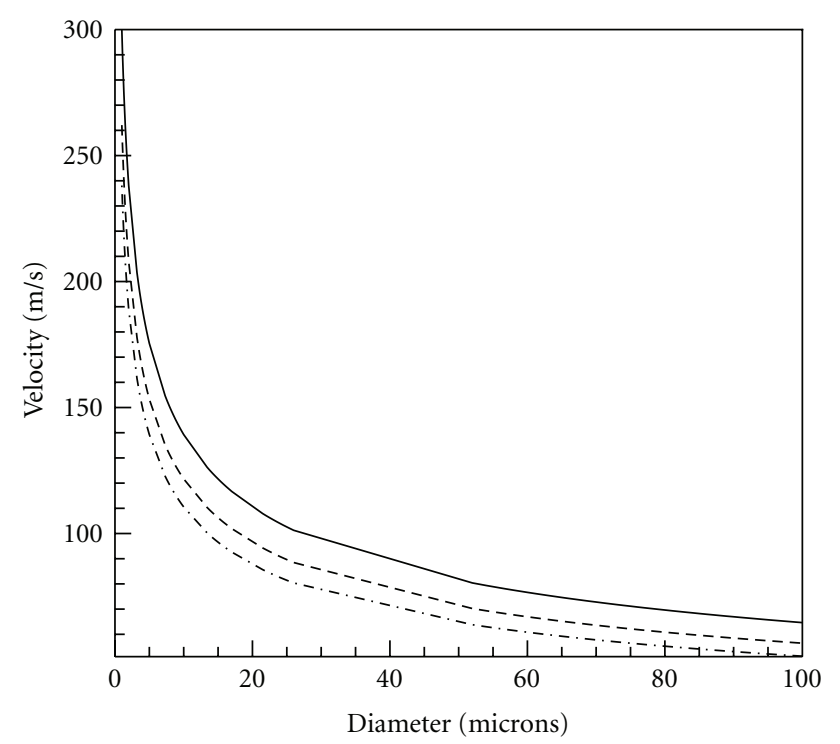

Density of gas

$-2 \mathrm{~kg} / \mathrm{m}^{3}$

$--3 \mathrm{~kg} / \mathrm{m}^{3}$

... $4 \mathrm{~kg} / \mathrm{m}^{3}$

FIgURe 2: Critical velocity versus particle diameter for various gas densities.

where $u_{r}=U_{\infty}-W$ represents the relative velocity between gas flow and boron particles. $W$ represents the velocity of boron particles. $d_{p}$ represents the diameter of boron particles.

While the surface tension is less than the tangential friction stress, aerodynamic shattering may happen. That is to say, part of liquid oxide layer is detached from the particle if the following equation comes into existence:

$$
\frac{\mathrm{We}}{\sqrt{\mathrm{Re}}} \geq \frac{8}{9} \frac{C_{1}}{G^{\prime \prime}(0)} .
$$

The critical velocity $u_{r \text { min }}$ can be reduced by the relation

$$
u_{r \min }=\left(\frac{64 C_{1}^{2} \sigma^{2}}{81 G^{\prime \prime}(0) \rho_{g} \mu_{g} d_{p}}\right)^{1 / 3} .
$$

Beyond $u_{r \text { min }}$, part of liquid oxide layer is detached from the particle and it is shifted to the rear. The formula above permits determination of the range of critical velocities for boron particle coated by a thin liquid oxide layer. The critical velocity versus particle diameter for various gas densities is shown in Figure 2. It may be seen that it is difficult for aerodynamic shattering to happen when the particle diameter is less than 15 microns.

The mass of fluid in the circumferential liquid oxide layer being swept along by the gas steam at a distance $x=\pi(R+$ $X) / 2$ from the stagnation point is

$$
\frac{d m}{d t}=\pi d_{p} \rho_{l} \int_{-\infty}^{0} u_{l} d y=\pi d_{p} \rho_{l} \sqrt{\frac{d_{p} u_{r} \mu_{l}}{\rho_{l}}} \int_{-\infty}^{0} L^{\prime}(\eta) d \eta .
$$

We can assume that the thickness of liquid oxide layer of boron particle is still uniformity along the uniformity after aerodynamic shattering. The following formula can be reduced

$$
\frac{d m}{d t}=\rho_{l} \pi d_{p}^{2} \frac{d X}{d t} .
$$

The change in the liquid oxide layer of boron particles due to aerodynamic shattering can be reduced:

$$
\frac{d X}{d t}=\sqrt{\frac{u_{r} \mu_{l}}{\left(d_{p} \rho_{l}\right)}} \int_{-\infty}^{0} L^{\prime}(\eta) d \eta
$$

2.2. Ignition Model of Boron Particle in High-Speed Flow. The results obtained above are used for developing an ignition model of boron particles, adopting a spherical form for the particles. For nonspherical particles, the aerodynamic shattering of liquid oxide layer is the same in principle, but the relevant expressions are more complicated.

In the analysis below we resort to King's model, based on the assumption that the exothermic reaction between boron and oxygen takes place at the boron-boron oxide interface as a result of oxygen diffusion across the melting oxide layer $[4,15]$. As the oxygen converts the boron into boric oxide, thickens the oxide layer, and releases heat, the oxide simultaneously vaporizes at the outer surface, this second process is endothermic and reduces the heating rate. Heat is added to or removed from the particle by convection and radiation, while inside the particle it is transferred by conduction from the surface to the center. Ignition occurs when the liquid oxide layer at the leading point of the particle is completely removed by the tangential friction stress effects $[4,15]$.

Step 1 .

$$
\begin{aligned}
& \mathrm{B}(\mathrm{s})+\frac{3}{4} \mathrm{O}_{2} \longrightarrow \frac{1}{2} \mathrm{~B}_{2} \mathrm{O}_{3}(\mathrm{l})+Q_{R X}, \\
& \mathrm{~B}(\mathrm{l})+\frac{3}{4} \mathrm{O}_{2} \longrightarrow \frac{1}{2} \mathrm{~B}_{2} \mathrm{O}_{3}(\mathrm{l})+Q_{R X 2},
\end{aligned}
$$

where $Q_{R X}=6.132 \times 10^{5} \mathrm{~J} / \mathrm{mole}, Q_{R X 2}=6.342 \times 10^{5} \mathrm{~J} /$ mole.

$$
w_{\mathrm{B}}=\frac{64.8 \times 10^{-8}(R+X)^{2} T_{p} P_{\mathrm{O}_{2}} e^{-22600 / T_{p}}}{X}(\mathrm{~mole} / \mathrm{s}),
$$

where $w_{\mathrm{B}}$ is the molar consumption rate of boron.

Step 2.

$$
\begin{gathered}
\mathrm{B}_{2} \mathrm{O}_{3}(\mathrm{l}) \longrightarrow \mathrm{B}_{2} \mathrm{O}_{3}(\mathrm{~g})-\Delta H_{\mathrm{vap}} \\
w_{E}=\frac{1.005 \times 10^{10}(R+X)^{2} \alpha e^{-44000 / T_{P}}}{T_{p}^{0.5}\left(1+4.5 \times 10^{7} \alpha P(R+X) /\left(T_{p} \mathrm{Nu}\right)\right)}(\mathrm{mole} / \mathrm{s})
\end{gathered}
$$

where $w_{E}$ is the molar rate of vaporization of boron, $\Delta H_{\mathrm{vap}}=$ $3.78 \times 10^{5} \mathrm{~J} /$ mole. 
Step 3.

$$
\begin{aligned}
& \mathrm{B}_{2} \mathrm{O}_{3}(\mathrm{l})+ \mathrm{H}_{2} \mathrm{O} \longrightarrow 2 \mathrm{HBO}_{2}-\Delta H_{H} \\
& \mathrm{E} w_{H}=9.15 \times 10^{-7} \frac{\mathrm{Nu}}{P}(R+X) T_{p}^{1 / 2} \exp \left[18.1\left(1-\frac{2100}{T_{p}}\right)\right] \\
& \times\{-0.15 \\
&+\left[0.0225+P_{\mathrm{H}_{2} \mathrm{O}}\right. \\
&\left.\left.\quad \times \exp \left(-18.1\left(1-\frac{2100}{T_{p}}\right)\right)\right]^{0.5}\right\}(\text { mole } / \mathrm{s}),
\end{aligned}
$$

where $w_{H}$ is the molar rate of removal of boric oxide, $\Delta H_{H}=$ $3.15 \times 10^{5} \mathrm{~J} /$ mole. The equation for particle radius and oxide layer thickness dynamic can be written as

$$
\begin{gathered}
\frac{d R}{d t}=-\frac{w_{\mathrm{B}} M_{\mathrm{B}}}{4 \pi R^{2} \rho_{\mathrm{B}}}, \\
\frac{d X}{d t}=\frac{\left(w_{\mathrm{B}} / 2-w_{E}-w_{\mathrm{H}}\right) M_{\mathrm{B}_{2} \mathrm{O}_{3}}}{4 \pi R^{2} \rho_{\mathrm{B}_{2} \mathrm{O}_{3}}} \\
-\sqrt{\frac{u_{r} \mu_{l}}{\left(d_{p} \rho_{l}\right)}} \int_{-\infty}^{0} L^{\prime}(\eta) d \eta .
\end{gathered}
$$

The first term on the right-hand side of formula (33) is due to King's model, and the second refers to our model of liquid oxide layer movement. For $u_{r}$ less than $u_{r \text { min }}$, the second term vanishes. The heat balance of liquid oxide layer is described by the equations (note that three different enthalpy balances must be employed depending on whether the particle temperature is less than, equal to, or greater than the melting point of boron, $2450 \mathrm{~K}$ ):

$$
\begin{array}{r}
\frac{d T_{p}}{d t}=\frac{Q_{1}}{\left(4 \pi R^{3} \rho_{\mathrm{B} c_{\mathrm{pBs}}} / 3\right)+4 \pi R^{2} X \rho_{\mathrm{B}_{2} \mathrm{O}_{3}} c_{p \mathrm{~B}_{2} \mathrm{O}_{3}}} \\
\left(T_{p}<2450 \mathrm{~K}, f=0\right), \\
\frac{d f}{d t}=\frac{Q_{1}}{4 \pi R^{3} \rho_{\mathrm{B}} \Delta H_{M} / 3} \\
\frac{\left(T_{p}=2450 \mathrm{~K}, 0<f<1\right),}{Q_{2}} \frac{Q_{p}}{\left(4 \pi R^{3} \rho_{\mathrm{B}} c_{\mathrm{pBl}} / 3\right)+4 \pi R^{2} X \rho_{\mathrm{B}_{2} \mathrm{O}_{3}} c_{p \mathrm{~B}_{2} \mathrm{O}_{3}}} \\
\left(T_{p}>2450 \mathrm{~K}, f=1\right),
\end{array}
$$

where $f$ is fraction of boron in the liquid phase, $T_{0}$ is free stream gas temperature, $T_{p}$ is particle temperature, $T_{\mathrm{RAD}}$ is surrounding radiation temperature, $Q_{1}, Q_{2}$ are heat transfer between particle and the surroundings, $Q_{1}=$ $w_{\mathrm{B}} Q_{R X}-w_{E} \Delta H_{\mathrm{vap}}-w_{H} \Delta H_{H}+4 \pi(R+X)^{2}\left[h\left(T_{\infty}-T_{p}\right)+\right.$ $\left.\sigma \varepsilon \alpha_{R}\left(T_{\mathrm{RAD}}^{4}-T_{\mathrm{p}}^{4}\right)\right], Q_{2}=w_{\mathrm{B}} Q_{R X 2}-w_{E} \Delta H_{\text {vap }}-w_{H} \Delta H_{H}+$ $4 \pi(R+X)^{2}\left[h\left(T_{\infty}-T_{p}\right)+\sigma \varepsilon \alpha_{R}\left(T_{\mathrm{RAD}}^{4}-T_{\mathrm{p}}^{4}\right)\right]$. The following values were used for other parameters appearing in equations above: $M_{\mathrm{B}}=10.82, \rho_{\mathrm{B}}=2.33 \times 10^{3} \mathrm{~kg} / \mathrm{m}^{3}, M_{\mathrm{B}_{2} \mathrm{O}_{3}}=69.64$, $\rho_{\mathrm{B}_{2} \mathrm{O}_{3}}=1.85 \times 10^{3} \mathrm{~kg} / \mathrm{m}^{3}, \mathrm{Pr}=0.72, \varepsilon=0.8, \alpha_{R}=1$, $\Delta H_{M}=2.1 \times 10^{3} \mathrm{~J} /$ mole, $h=1.46 \times 10^{-2} \times \mathrm{Nu} \times T_{\infty}^{0.8} /$ $(R+X) \mathrm{J} /\left(\mathrm{m}^{2} \cdot \mathrm{s} \cdot \mathrm{K}\right), \mathrm{Nu}=2+0.6 \mathrm{Re}^{1 / 2} \operatorname{Pr}^{1 / 3}, c_{p \mathrm{Bs}}=2130+$ $0.294 T_{p} \mathrm{~J} /(\mathrm{kg} \cdot \mathrm{K}), c_{p \mathrm{Bl}}=2.84 \times 10^{3} \mathrm{~J} /(\mathrm{kg} \cdot \mathrm{K}), c_{p \mathrm{~B}_{2} \mathrm{O}_{3}}=$ $1.84 \times 10^{3} \mathrm{~J} /(\mathrm{kg} \cdot \mathrm{K})$.

\section{Results and Discussion}

The model of boron ignition developed in this study involves nine independent parameters, value of which must be input to the resulting numerical computer program for prediction of particle ignition time and minimum gas temperature required for particle ignition [18]. There variables are relative velocity between gas flow and boron particles, initial oxide thickness, initial particle temperature, initial particle size, ambient temperature (surroundings gas temperature), effective surroundings radiation temperature, ambient pressure, water vapor mole fraction, and oxygen mole fraction. As part of this study, each of the above independent variables has been systematical varied to determine its effect on whether the particle will ignite and, if so, what the ignition time will be.

3.1. Effect of Ambient Temperature. In Figure 3 plots of oxide layer thickness, particle temperature, particle radius, and fraction boron melted versus time presented for a typical case in which the numerical analysis predicts particle ignition. The particle treated is 10 microns in radius with an initial oxide layer thickness of 0.1 micron and initial temperature of $1800 \mathrm{~K}$. The pressure is $0.5 \mathrm{MPa}$, the oxygen mole fraction is 0.2 , the water vapor mole fraction is zero, and the relative velocity between gas flow and boron particles is $100 \mathrm{~m} / \mathrm{s}$. The ambient temperature and effective surroundings radiation temperature are both $2100 \mathrm{~K}$.

As may be shown in Figure 3, once the particle temperature exceeds approximately $2000 \mathrm{~K}$, the oxide evaporation and the change due to aerodynamic shattering rise above the oxide generation rate, resulting in thinning of the oxide layer. The boron particle temperature continue to increase as the oxide layer thins while the boron melting point is reached. At this point the oxide thickness and particle temperature remain constant until the boron melts. After the boron particle has melted, the particle temperature resumes its rise and the oxide layer continues to thin until the particle ignite. Compared with King's model, as the ignition model of boron particles is formulated for the oxide layer removal by considering that it results from a boundary layer stripping mechanism, the oxide layer thickness thins at all times during the particle ignition and lower the ignition time.

In Figure 4, similar results are presented for a case identical except for reduction of the ambient temperature and effective surroundings radiation temperature by $200 \mathrm{~K}$ to 


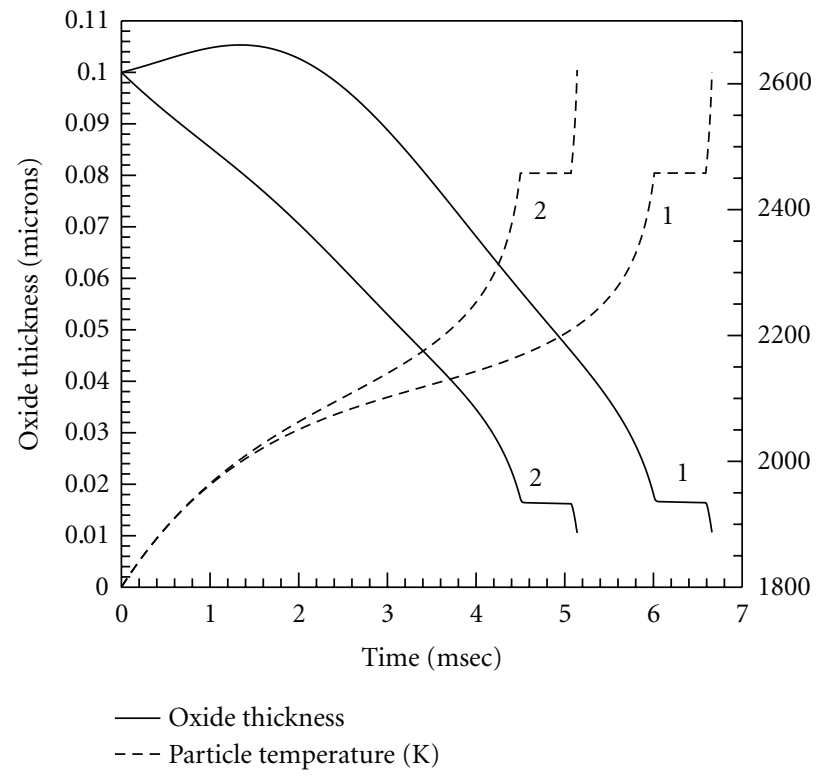

(a)

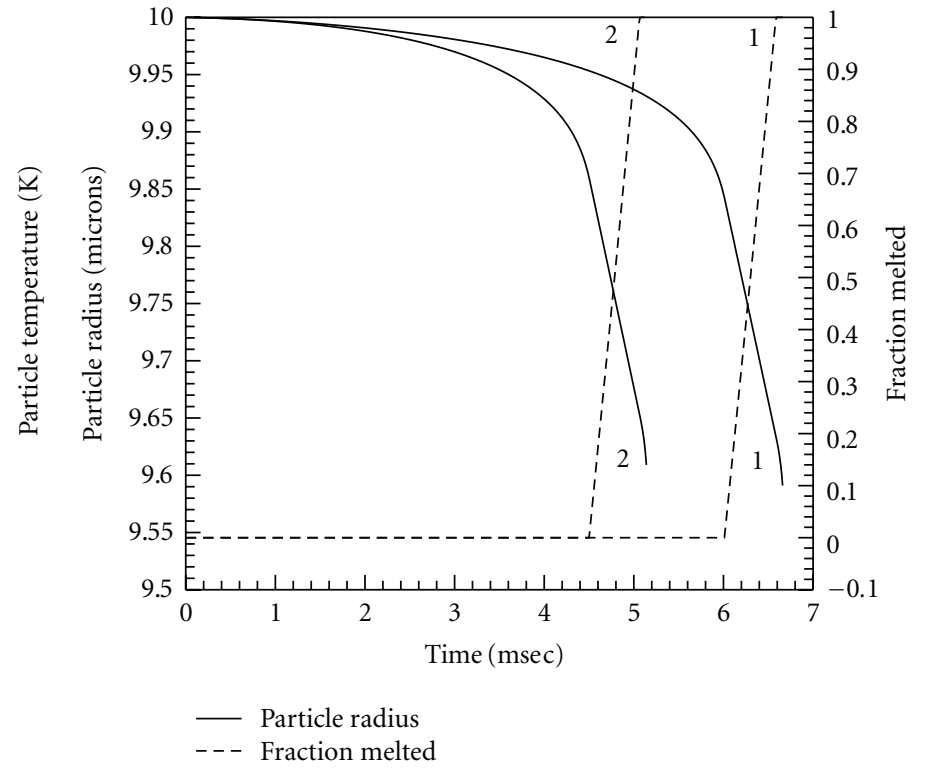

(b)

Figure 3: Predicted time dependence of important variables for particle which ignites at ambient temperature of $2100 \mathrm{~K}$ ((a) King's model (b) our model with film moving).

$1900 \mathrm{~K}$. The initial stages of the ignition process are quite similar. However, heat losses to the surroundings when the particle temperature rises above the $1900 \mathrm{~K}$ ambient temperature are sufficient to retard the evaporation rate sufficiently that it drops back to the generation rate with the result that the oxide layer ceases thinning. In this case, a stable quasi-steady-state is reached. The boron particle temperature remains a steady value, and the ignition does not occur.

3.2. Effect of Total Pressure and Oxygen Mole Fraction. The effects of total pressure and oxygen mole fraction in the gasfree stream on minimum gas temperature required for particle ignition and ignition time are shown in Figures 5 and 6 . These calculations were all performed for particles of 10 microns radius with an initial temperature of $1800 \mathrm{~K}$ and initial oxide thicknesses of 0.1 microns. The calculations were carried out for a $100 \mathrm{~m} / \mathrm{s}$ gas stream in the surroundings with water vapor mole fraction of zero at the conditions that ambient temperature and effective surroundings radiation temperature are both $2100 \mathrm{~K}$. Similar trends were noted with other particle sizes and initial oxide thicknesses.

As shown in Figure 5, decreased total pressure lowers the gas temperature required for ignition at low oxygen mole fractions but raises the required gas temperature at high oxygen mole fractions. These fairly complex dependencies result from interaction of the effect of oxygen mole fraction on the oxide generation rate and the effect of total pressure on the oxide removal rate. Increase of the total pressure intensified oxygen diffusion through the oxide layer but reduced the oxide vaporizing rate. It also leads to increased gas density, with the attendance opposite influence on tangential friction stress [15]. Similar effects on the ignition time at a fixed gas temperature and velocity as functions of total pressure and oxygen mole fraction are shown in Figure 6. At high oxidizer mole fractions, ignition time reduces with reducing total pressure while at low oxidizer mole fractions the pressure dependency is reversed.

3.3. Effect of Particle Radius. The effect of particle radius on ignition time was also studied. In Figure 7, predictions of ignition time versus particle radius for particle which are predicated to ignite are presented for several gas temperatures ranging from $2050 \mathrm{~K}$ to $2200 \mathrm{~K}$, and the radiation surroundings temperature is set equal to ambient gas temperature. The particles (radius size range from 5 to 20 microns with an initial oxide layer thickness of 0.1 micron) were assumed to be preheated to $1800 \mathrm{~K}$ prior to ejection gas stream. The pressure is $0.5 \mathrm{MPa}$, the oxygen mole fraction is 0.2 , the water vapor mole fraction is zero, and the relative velocity between gas flow and boron particles is $100 \mathrm{~m} / \mathrm{s}$. As shown in Figure 7, the ignition time decreases monotonically with decreasing particle radius due to the decrease in particle massto-surface area ratio with decreasing radius. For the higher ambient gas temperature, ignition time is shorter.

3.4. Effect of Water Vapor Mole Fraction. The effect of water vapor mole fraction in the gas-free stream on ignition time is shown in Figure 8. These calculations were all performed for particles of 10 microns radius with an initial temperature of $1800 \mathrm{~K}$ and initial oxide thicknesses of $0.1 \mathrm{mi}-$ crons. The pressure is $0.5 \mathrm{MPa}$, the oxygen mole fraction is 0.2 , and the relative velocity between gas flow and boron particles is $100 \mathrm{~m} / \mathrm{s}$. The ambient temperature and effective surroundings radiation temperature are both $2100 \mathrm{~K}$. As shown in Figure 8, the ignition time decreases monotonically with increasing water vapor mole fraction due to treating water 


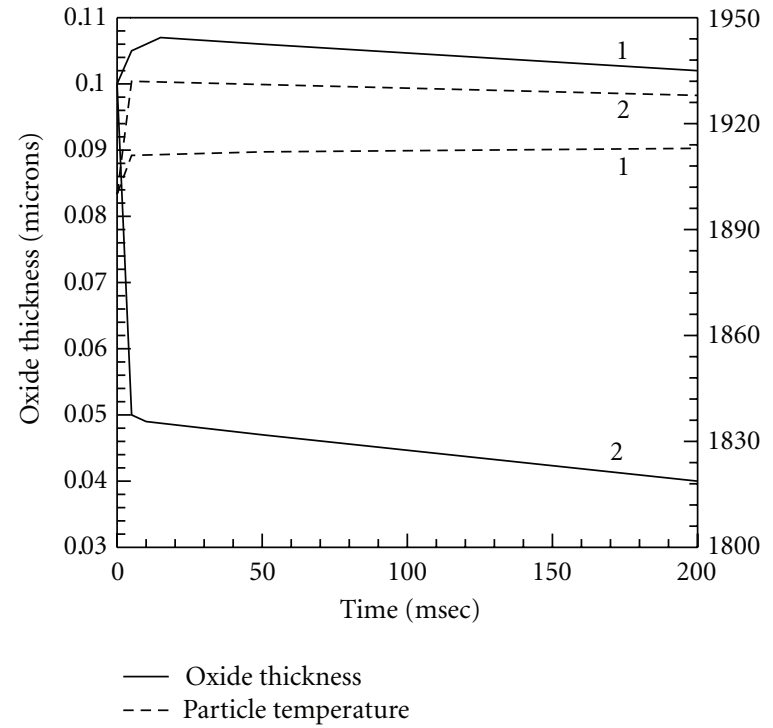

(a)

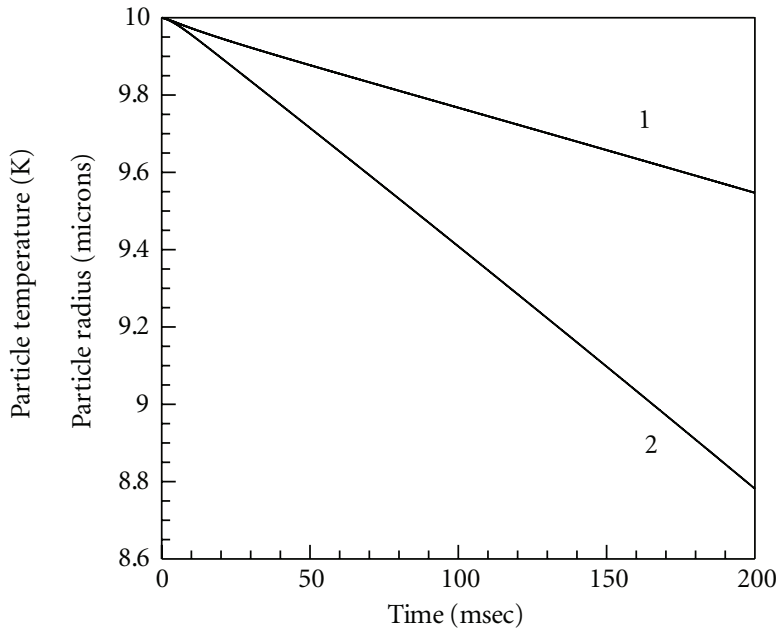

(b)

Figure 4: Predicted time dependence of important variables for particle which ignites at ambient temperature of $1900 \mathrm{~K}$ (a) King's Model (b) our model with film moving).

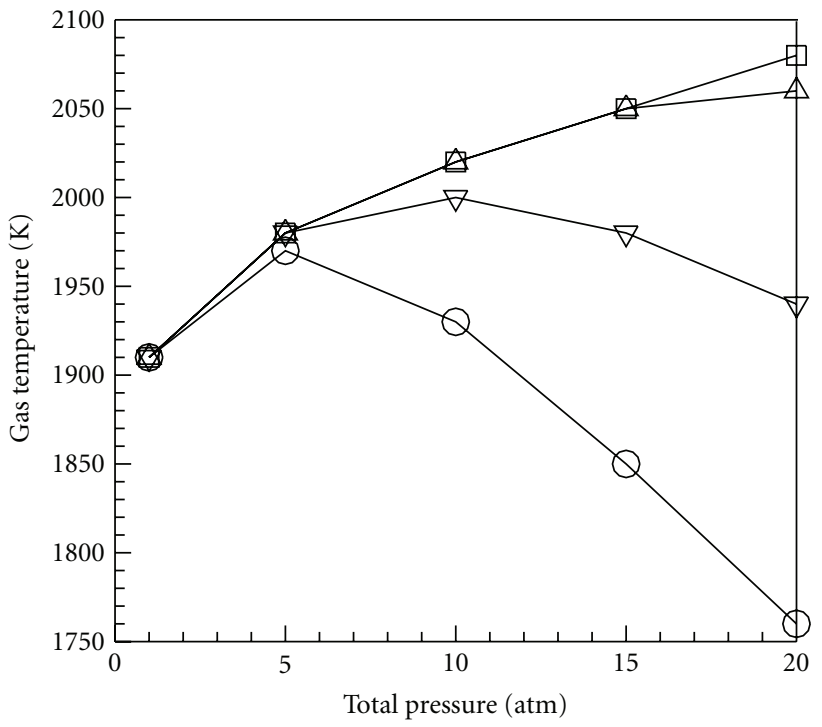

$\mathrm{O}_{2}$ mole fraction

$\begin{array}{llll}\square & 0.1 & \nabla & 0.5 \\ \triangle & 0.2 & \bigcirc & 1\end{array}$

FIGURE 5: Minimum gas temperature required for ignition versus total pressure for various oxygen mole fractions.

vapor as reacting by a diffusion-limited reaction with the boric oxide to aid in removal of the oxide layer.

\section{Conclusions}

The shearing action exerted by the high-speed flow causes a boundary layer to be formed in the surface of the liquid

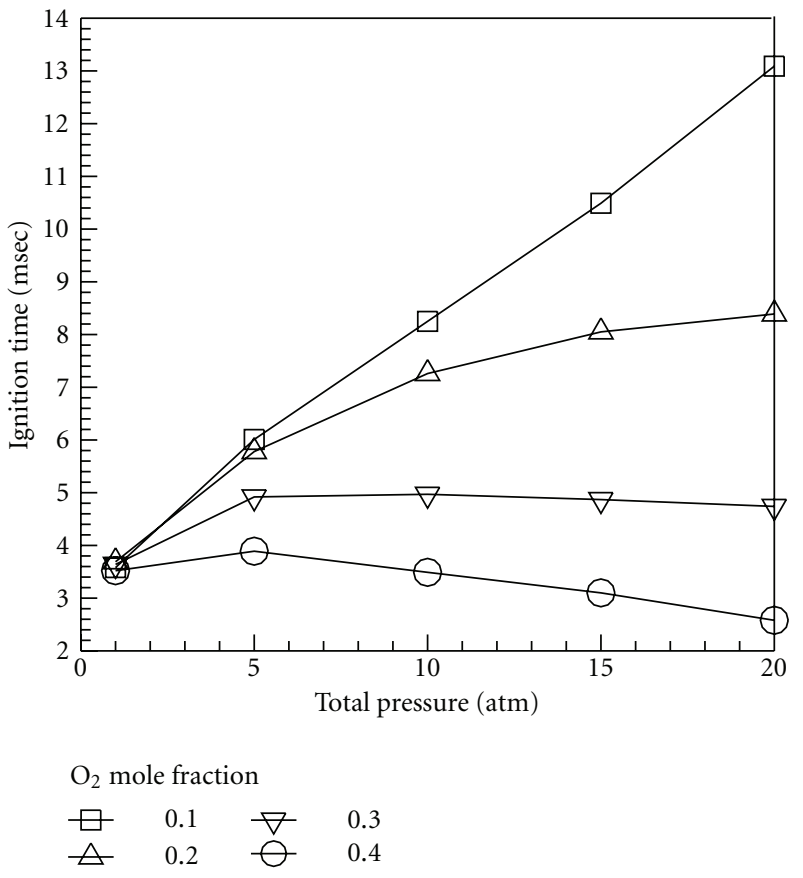

FIGURE 6: Ignition time versus total pressure for various oxygen mole fractions.

oxide layer, and the stripping away of this layer accounts for the accelerated ignition of the boron particle. It is shown that migration of the liquid oxide layer on the front half-surface of the particle can be derived. The rate of disintegration is founded by integrating over the thickness of the liquid boundary layer to determine the mass flux leaving the boron particle surface at its equator. An ignition model of 


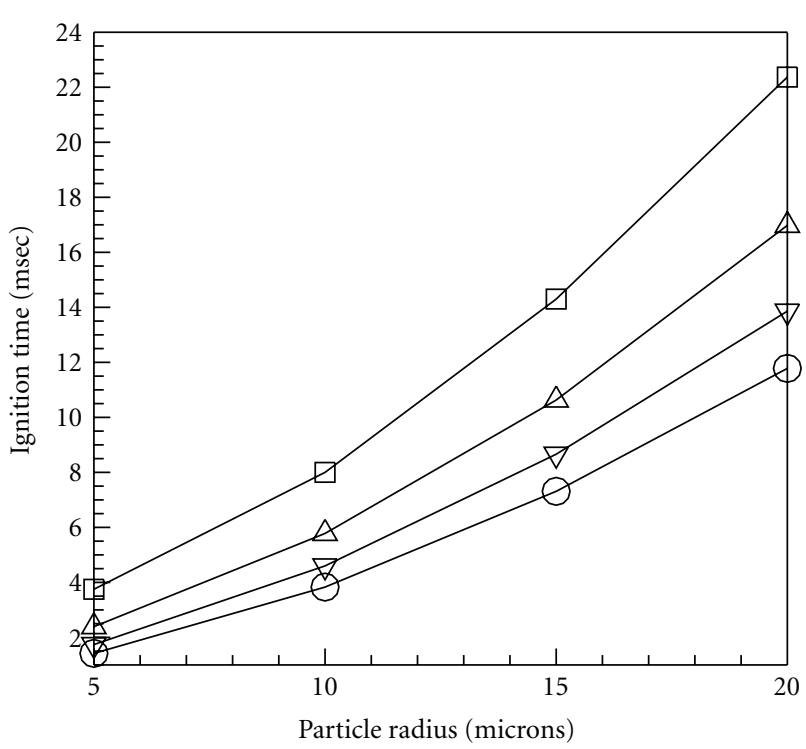

Free stream gas temperature $(\mathrm{K})$

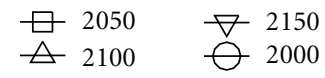

FIGURE 7: Ignition time versus particle radius for various ambient gas temperatures.

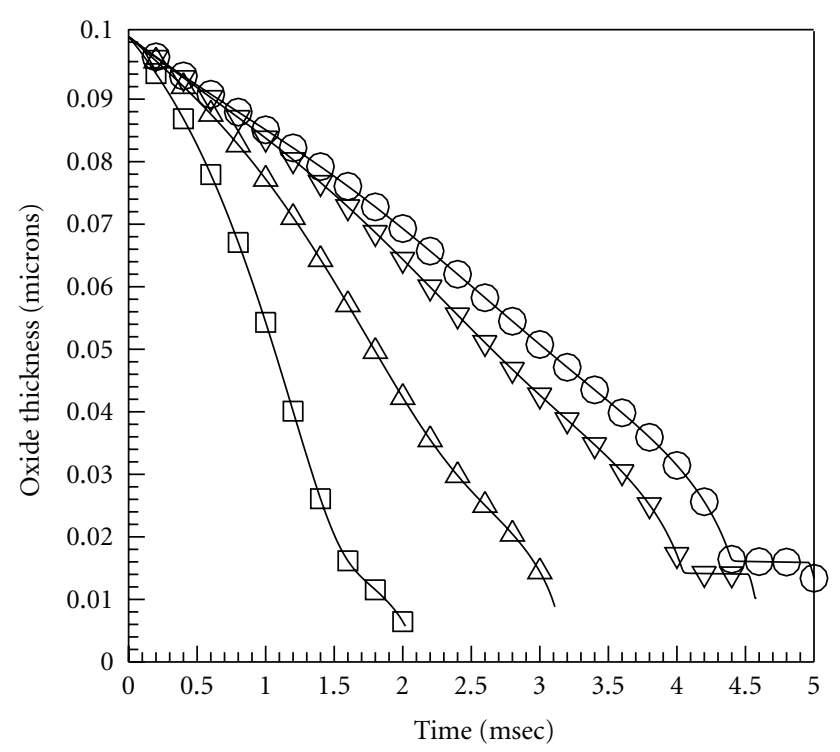

$\mathrm{H}_{2} \mathrm{O}$ mole fraction

$\begin{array}{llll}\square & 0.2 & \nabla & 0.01 \\ \triangle & 0.05 & \bigcirc & 0.002\end{array}$

FIGURE 8: Oxide layer thickness versus time for various water vapor mole fractions.

boron particles is formulated for the oxide layer removal by considering that it results from a boundary layer stripping mechanism. Effects of various parameters on boron particle ignition were studied with this model. Compared with King's model, as the ignition model of boron particles is formulated for the oxide layer removal by considering that it results from a boundary layer stripping mechanism, the oxide layer thickness thins at all times during the particle ignition and lower the ignition time. The present results support a physical mechanism through which preheated boron particles in gas generator of ducted rockets can be ignited in the secondary chamber by ejection into a high-speed stream.

\section{Acknowledgments}

The support of the China Sponsorship Council (CSC) (Grant no. 51006118) is gratefully acknowledged. J. X. Hu thanks Benveniste Natan of Technion-Israel Institute of Technology for the help and encouragement.

\section{References}

[1] R. S. Fry, "A century of ramjet propulsion technology evolution," Journal of Propulsion and Power, vol. 20, no. 1, pp. 27-58, 2004.

[2] B. Natan and A. Gany, "Ignition and combustion boron particles in the flow field of a solid fuel ramjet," Journal of Propulsion and Power, vol. 7, no. 1, pp. 37-43, 1991.

[3] C. L. Yeh and K. K. Kuo, "Ignition and combustion of boron particles," Progress in Energy and Combustion Science, vol. 22, no. 6, pp. 511-541, 1996.

[4] M. K. King, "Ignition and combustion of boron particles and clouds," Journal of Spacecraft and Rockets, vol. 19, no. 4, pp. 294-306, 1982.

[5] D. Meinköhn, "Boron particle ignition and the marangoni effect," Combustion Science and Technology, vol. 176, no. 9, pp. 1493-1536, 2004.

[6] G. Mohan and F. A. Williams, "Ignition and combustion of boron in $\mathrm{O}_{2}$ /inert atmospheres," AIAA Journal, vol. 10, no. 6, pp. 776-783, 1972.

[7] S. C. Li and F. A. Williams, "Ignition and combustion of boron particles," International Journal of Energetic Materials and Chemical Propulsion, vol. 2, no. 1-6, pp. 248-271, 1991.

[8] A. Macek and J. M. Semple, "Combustion of boron particles at atmospheric pressure," Combustion Science and Technology, vol. 1, no. 3, pp. 181-191, 1969.

[9] W. Zhou, R. A. Yetter, F. L. Dryer, H. Rabitz, R. C. Brown, and C. E. Kolb, "Multi-phase model for ignition and combustion of boron particles," Combustion and Flame, vol. 117, no. 1-2, pp. 227-243, 1999.

[10] J. X. Hu, Z. X. Xia, and D. Q. Wang, "Study on burning rate of boron particles in secondary chamber of ducted rocket under forced convection conditions," Journal of Solid Rocket Technology, vol. 30, no. 1, pp. 21-25, 2007.

[11] R. O. Foelsche, R. L. Burton, and H. Krier, "Ignition and combustion of boron particles in hydrogen/oxygen explosion products," AIAA 97-0127, 1997.

[12] M. A. Gurevich, I. M. Kir'yanov, and E. S. Ozerov, "Combustion of individual boron particles," Combustion, Explosion, and Shock Waves, vol. 5, no. 2, pp. 150-153, 1969.

[13] D. Meinköhn, "Liquid oxide surface layers in metal combustion," Combustion Theory and Modelling, vol. 8, no. 2, pp. 315338, 2004.

[14] D. Meinköhn, "The effect of particle size and ambient oxidizer concentration on metal particle ignition," Combustion Science and Technology, vol. 181, no. 8, pp. 1007-1037, 2009.

[15] A. Povitsky and Y. Goldman, "Boron particle ignition in highspeed flow," in Proceedings of the 29th AIAA Joint Propulsion Conference, vol. 2202, AIAA paper 93, 1993. 
[16] A. A. Ranger and J. A. Nicholis, "Aerodynamic shattering of liquid drops," AIAA Journal, vol. 7, no. 2, pp. 285-290, 1969.

[17] M. Zhou and F. C. Zhuang, "Aerodynamic shattering of liquid drops using a boundary layer stripping mechanism," Journal of National University of Defense Technology, vol. 13, no. 3, pp. 29-33, 1991.

[18] M. K. King, "Boron particle ignition in hot gas stream," Combustion Science and Technology, vol. 8, no. 5-6, pp. 254-273, 1974. 

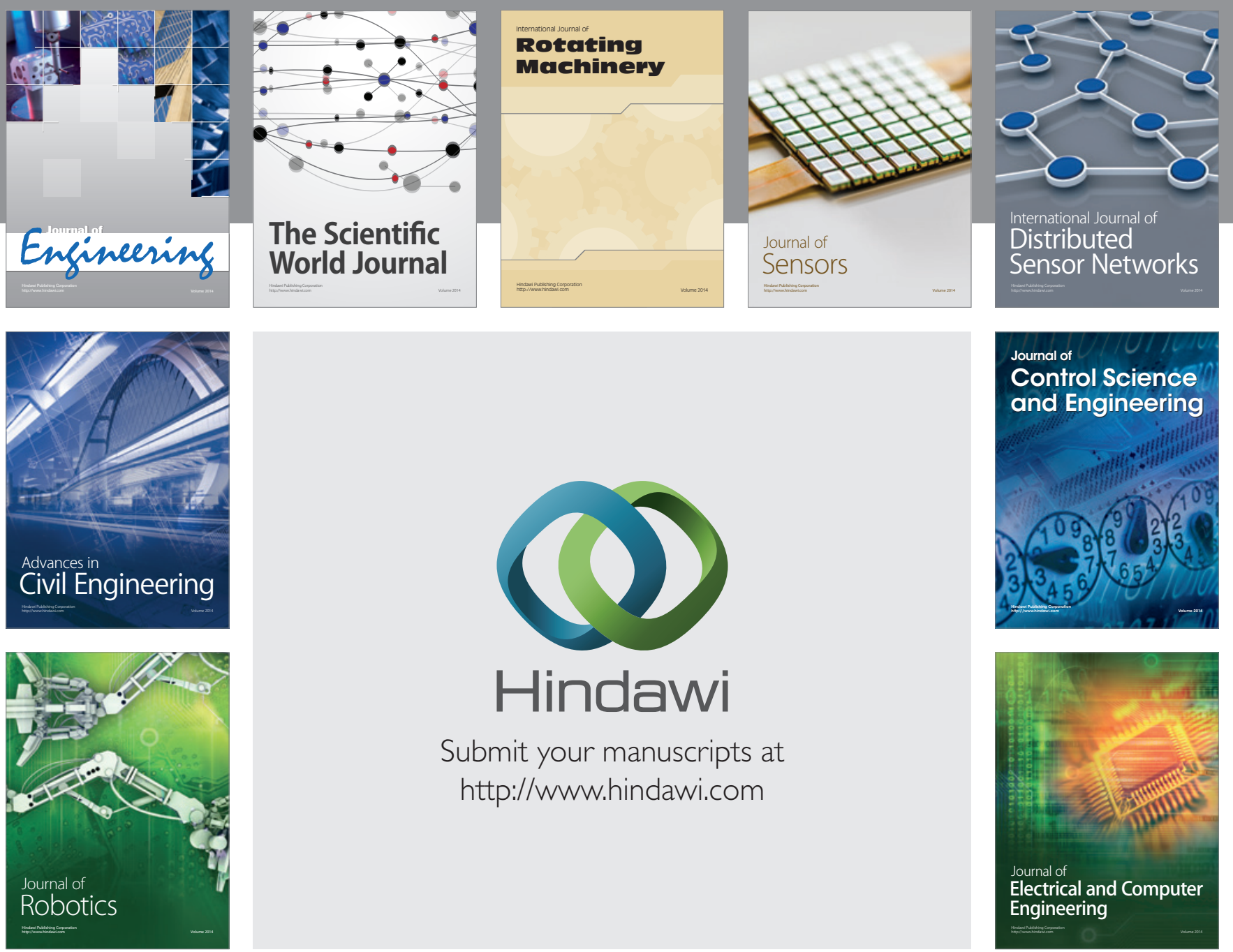

Submit your manuscripts at

http://www.hindawi.com
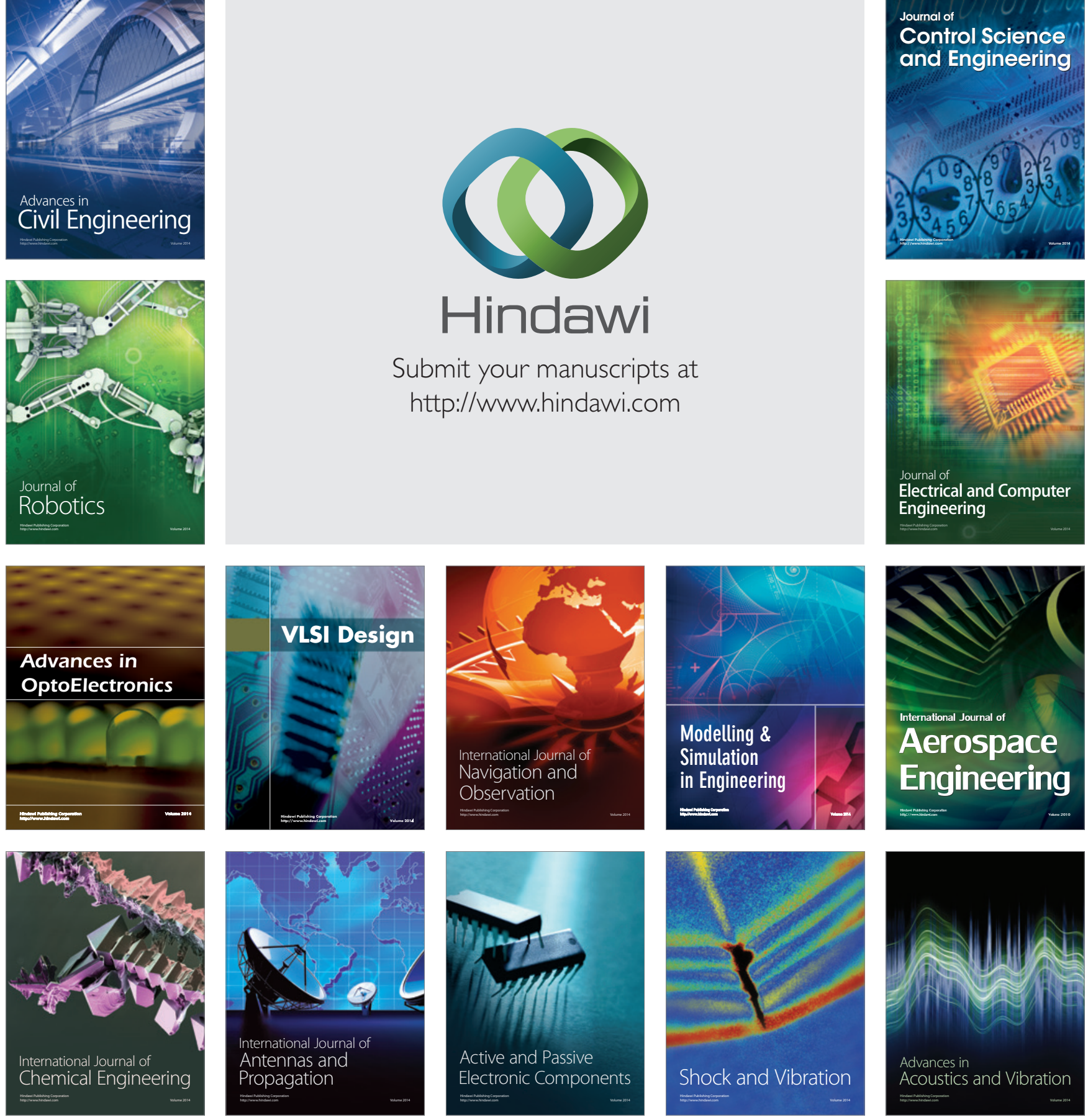